2016-09-19

Ocean acidification reduces demersal zooplankton that reside in tropical coral reefs

Smith, JN

http://hdl.handle.net/10026.1/8121

10.1038/nclimate3122

Nature Climate Change

Springer Science and Business Media LLC

All content in PEARL is protected by copyright law. Author manuscripts are made available in accordance with publisher policies. Please cite only the published version using the details provided on the item record or document. In the absence of an open licence (e.g. Creative Commons), permissions for further reuse of content should be sought from the publisher or author. 
- $\quad$ "This is the author's accepted manuscript. Please cite the final published version of this work (the version of record) published by Springer Nature in Nature Climate Change (19 September 2016) available at: http://dx.doi.org/10.1038/nclimate3122. This work is made available online in accordance with the publisher's policies. Please refer to any applicable terms of use of the publisher."

\section{Ocean acidification reduces demersal zooplankton that reside in tropical coral reefs}

Joy N. Smith*1,2,3,4, Glenn De'ath1', Claudio Richter²,3, Astrid Cornils², Jason M. Hall-Spencer ${ }^{4,5}$, Katharina E. Fabricius ${ }^{1}$

1 Australian Institute of Marine Science, Townsville, Queensland, Australia

2 Alfred Wegener Institute Helmholtz Centre for Polar and Marine Research, Bremerhaven, Germany

3 University of Bremen, Germany

4 Plymouth University, UK

5 Shimoda Marine Research Centre, University of Tsukuba, Japan

*corresponding author's email address: JZ.Smith@aims.gov.au

\section{Abstract}

The in situ effects of ocean acidification on zooplankton communities remain largely unexplored. Using natural volcanic $\mathrm{CO}_{2}$ seep sites around tropical coral communities, we show a three-fold reduction in the biomass of demersal zooplankton in high- $\mathrm{CO}_{2}$ sites compared to sites with ambient $\mathrm{CO}_{2}$. Differences were consistent across two reefs and three expeditions. Abundances were reduced in most taxonomic groups. There were no regime shifts in zooplankton community composition and no differences in fatty acid composition between $\mathrm{CO}_{2}$ levels, suggesting ocean acidification affects the food quantity but not the quality for nocturnal plankton feeders. Emergence trap data show that the observed reduction in demersal plankton may be partly attributable to altered habitat. Ocean acidification changes coral community composition from branching to massive bouldering coral species, and our data suggest that bouldering corals represent inferior daytime shelter for demersal zooplankton. Since zooplankton represent a major source of nutrients for corals, fish, and 
other planktivores, this ecological feedback may represent a novel mechanism of how coral reefs will be affected by progressive ocean acidification.

\section{Main text}

Increased levels of anthropogenic $\mathrm{CO}_{2}$ in the atmosphere catalyze processes that can collectively impact zooplankton communities. Concurrent with ocean warming, absorbed carbon dioxide changes the ocean chemistry by reducing seawater $\mathrm{pH}$, carbonate ion concentrations, and saturation states of calcium carbonate in a process called ocean acidification ${ }^{1-4}$.

Although the ramifications of ocean acidification on zooplankton communities are poorly understood, their impacts are potentially far-reaching due to their pivotal role in marine ecosystems and the carbon cycle. Zooplankton are a major food source for planktivores, and they also support bacterial and phytoplankton production through their excretion of nitrogen and phosphorus compounds ${ }^{5}$. Furthermore, they contribute to the biological pump as consumers of $\mathrm{CO}_{2}$-fixing phytoplankton ${ }^{6}$. The subsequent sedimentation and burial of fecal pellets and zooplankton carcasses act as a sink for $\mathrm{CO}_{2}$ that may help mitigate $\mathrm{CO}_{2}$ emissions. Thus, in order to support predictions of the future effects of ocean acidification on marine benthic and pelagic ecosystems and $\mathrm{CO}_{2}$ fluxes, it is essential to understand the effects of ocean acidification on zooplankton communities.

Ocean acidification studies of zooplankton have primarily focused on single-species laboratory experiments, with very few of the $>7000$ described species ${ }^{7}$ having been studied to date. Studies have reported severe direct effects 
on some calcifying plankton ${ }^{8-10}$, attributable to the increased energy requirements needed to acquire carbonate ions as building blocks for calcification. In contrast, existing studies suggest that non-calcifiers like copepods are generally not directly affected by ocean acidification ${ }^{11-14}$. Although single-species experiments advance our understanding of the underlying mechanisms governing the direct effects of elevated $\mathrm{CO}_{2}$ on organisms, they have limited capacity to predict the effect of ocean acidification on entire communities ${ }^{15}$. This is particularly true for zooplankton considering that calcifying species usually comprise a small proportion of the communities, and many of the non-calcifying species evaluated were generalists that are naturally found under wide ranges of environmental conditions and hence tolerate laboratory conditions ${ }^{16-19}$.Therefore, to understand how ocean acidification may impact zooplankton in the future, entire communities need to be evaluated in situ under ocean acidification conditions.

The long-term effects of elevated carbon dioxide on marine ecosystems and entire communities have been studied at a few unique submarine volcanic $\mathrm{CO}_{2}$ seeps. We used two such volcanic seeps in Papua New Guinea as natural laboratories, which release nearly pure $\mathrm{CO}_{2}$ into tropical fringing coral reefs.

Coral reefs are highly vulnerable to ocean acidification because of the sensitivity of their foundation species, namely corals and crustose coralline algae, and the dissolution of reef carbonate substrata at reduced $\mathrm{pH}^{20-22}$. If the zooplankton that live in coral reefs are impacted by ocean acidification too, this could further strain the already jeopardized coral reefs. 
The bulk of zooplankton in coral reefs are demersal, meaning the organisms live on or above substrata during the day and migrate into the water column at night ${ }^{23,24}$. We compared zooplankton communities residing near $\mathrm{CO}_{2}$ seeps with communities living at control sites. Seawater at the high- $\mathrm{CO}_{2}$ seeps averaged $7.8 \mathrm{pH}$ ( $\mathrm{pH}$ at total scale; for spatial and temporal variability see Supplementary Fig. 1), while at the adjacent control sites (without seep activity) it averaged $8.0 \mathrm{pH}$ (refs. ${ }^{20,25}$ ). All study sites had similar seabed topography, depth 2-3 m, tidal range $<0.9 \mathrm{~m}$, and longshore currents $2-4 \mathrm{~cm} \mathrm{~s}^{-1}$, with an average water residence time of $\sim 2.5$ hrs over all seeps. We compared demersal zooplankton abundances, biomass, and community compositions along high- $\mathrm{CO}_{2}$ and control sites at $\mathrm{CO}_{2}$ seeps on Dobu and Upa-Upasina reefs using horizontal surface net tows and emergence traps on three separate expeditions.

\section{Loss of reef-associated demersal zooplankton due to ocean acidification}

At night, when the demersal zooplankton emerged, zooplankton had consistently higher biomass $\left(\mathrm{mg} \mathrm{m}^{-3}\right)$ at the control sites compared to the high$\mathrm{CO}_{2}$ sites. Across the two reefs (Dobu and Upa-Upasina) and all three expeditions, control sites had on average $2.83(\mathrm{SE}=0.19)$ times greater zooplankton biomass than high- $\mathrm{CO}_{2}$ sites (range: $1.45-4.85, \mathrm{~N}=24$; Fig. 1a). At each reef, zooplankton biomass was low and similar between $\mathrm{CO}_{2}$ regimes during the day. On average, control sites had $9.33(\mathrm{SE}=1.25)$ times more zooplankton biomass at night than during the day, whereas for the high- $\mathrm{CO}_{2}$ sites that ratio was $3.14(\mathrm{SE}=0.39)$. There was no difference in zooplankton biomass 
during the day or at night between the offshore control and offshore high- $\mathrm{CO}_{2}$ sites. Offshore sites were $\sim 200-300 \mathrm{~m}$ from the coastline at water depths of 50$70 \mathrm{~m}$. At night, biomass at the offshore sites averaged $3.66(\mathrm{SE}=1.15)$ times less than the control sites, confirming that the bulk of the zooplankton were indeed resident to the reefs. The zooplankton composition also differed between offshore waters and the reef. Biomass of bulk zooplankton at control sites remained higher than at high- $\mathrm{CO}_{2}$ sites throughout the entire night, and the diurnal migration patterns were similar between control and high- $\mathrm{CO}_{2}$ sites (Fig. 1b).

For individual zooplankton taxa, our analyses revealed significant $(p<$ 0.05 ) reductions in abundances (individuals $\mathrm{m}^{-3}$ ) at the high- $\mathrm{CO}_{2}$ sites compared to control sites for most taxa, and no taxon preferred the high- $\mathrm{CO}_{2}$ sites (Fig. 2). For example, for the copepod family Pontellidae, abundance at the high- $\mathrm{CO}_{2}$ sites was 0.17 of that at the control sites with a $95 \%$ confidence interval of $(0.09$, 0.32). Additional to the $\mathrm{CO}_{2}$ effects, abundances of some taxa also varied significantly between sites or between expeditions. A few taxa (Centropagidae, Oithonidae, Cumacea) remained unaffected by $\mathrm{CO}_{2}$ (ratios $>1.0$, but standard errors including 1.0). For all other taxa, the values and $95 \%$ confidence intervals remained below 1.0, with taxonomic groups at the high- $\mathrm{CO}_{2}$ sites reduced. Abundances for copepod taxa at the high- $\mathrm{CO}_{2}$ were between $12-71 \%$ of those at the control sites, and for non-copepod taxa this decline in abundances at the high- $\mathrm{CO}_{2}$ sites ranged between $19-48 \%$. A ranking of the sensitivity of taxa showed that $10 \%$ of the taxa at the high- $\mathrm{CO}_{2}$ sites had declined to $<20 \%$ of the 
control abundances, while $84 \%$ of the taxa had declined to $<50 \%$. The most sensitive copepod taxa were Monstrilloda and Pontellidae (abundance ratios = 0.12 and 0.17 , respectively), and amphipods and ostracods were the most sensitive non-copepod taxa (abundance ratios $=0.19$ for both).

Most resident copepod taxa were reduced in abundance, including those families predicted by laboratory experiments to be resilient to ocean acidification. One of the dominant copepod families was Acartiidae, a widely distributed group that is also known to reside demersally within coral reefs ${ }^{16}$. Acartiidae abundance was 14 times higher at the control than the high- $\mathrm{CO}_{2}$ sites, despite previous short-term $\mathrm{CO}_{2}$ exposure laboratory experiments suggesting that the survival, body size, developmental speed, egg production, and hatching rates of Acartiidae are negligibly affected by the magnitude of seawater $\mathrm{pH}$ change expected by the end of the century $11,26,27$. This discrepancy of results highlights the need for field observations to validate laboratory predictions of direct and indirect impacts of rising $\mathrm{CO}_{2}$ levels.

Abundances of all non-copepod zooplankton taxa were also reduced under ocean acidification, except for cumacean crustaceans. Also, zooplankton taxa that remain planktonic their entire lives (e.g. all copepods, amphipods, isopods, mysids, ostracods), and larval zooplankton that grow into larger organisms (e.g. decapod larvae, echinoderm larvae), were all reduced under ocean acidification, although to varying degrees. 


\section{No major shifts in zooplankton communities were caused by ocean acidification}

Community analyses showed that there was no species turnover between the control and high- $\mathrm{CO}_{2}$ sites. There was neither species replacement nor any taxon that proliferated in the high- $\mathrm{CO}_{2}$ environment. There were, however, slight shifts in the percent composition of the already present taxa within the community since each taxon had a slightly different sensitivity to ocean acidification, but no new groups filled the niche or replaced other taxa in the $\mathrm{CO}_{2}$ impacted habitat. Zooplankton communities were distinct between Upa-Upasina and Dobu reefs and between expeditions, but all had similar reactions to ocean acidification: all taxonomic groups present in the control sites persisted in the high- $\mathrm{CO}_{2}$ sites, albeit at much lower abundances (Fig. 3).

There were also no major shifts in the biochemical composition of the zooplankton community. Specifically, the fatty acid content of bulk zooplankton samples was not different between the control and high- $\mathrm{CO}_{2}$ sites during the second expedition (permanova: $p=0.440$ ), although it did vary between the two reefs $(p=0.001)$. Zooplankton predators, including carnivorous plankton, corals and fishes, are thus likely to encounter quantitative but not biochemical changes in zooplankton food between high- $\mathrm{CO}_{2}$ and control sites.

\section{Reduced habitat complexity causes abundance loss for some zooplankton taxa}


The causes of reduced zooplankton abundances at high- $\mathrm{CO}_{2}$ could be due to physiological, behavioral, or ecological effects, including habitat loss and changes in the food web. At the high- $\mathrm{CO}_{2}$ sites, coral cover is maintained with $31 \%$ and $33 \%$ hard coral coverage at the control and high- $\mathrm{CO}_{2}$ sites, yet the composition of coral communities shifts from branching corals to massive bouldering corals with massive bouldering corals more than doubling (from $10.7 \%$ at the control sites to $24.9 \%$ cover at the high- $\mathrm{CO}_{2}$ sites), while the structurally complex corals were reduced three fold (from $12.9 \%$ to $4.3 \%$ cover $)^{20}$. Coral rubble remained similar with $3.0 \%$ cover at the control sites and $2.6 \%$ cover at the high- $\mathrm{CO}_{2}$ sites. Such loss in complexity has consequences for the organisms that rely on corals as habitat ${ }^{28}$. To determine substrata preferences of the various zooplankton taxa for their daytime residence, emergence traps were placed over $1.0 \mathrm{~m}$ squares dominated by three different reef substrata (branching coral, massive boulder coral, and coral rubble). Emergence traps captured demersal zooplankton at night during their vertical migration when they swam into dimly illuminated (3 lumens) codends. Traps were retrieved 2-3 hours after dark, yielding a mean of 13,677 (SE =1,948) individual zooplankton per trap at the control sites and 6,504 $(\mathrm{SE}=787)$ at the high- $\mathrm{CO}_{2}$ sites. The exact composition of the substrata within these squares was determined from photographs, distinguishing seven substrata types (branching coral, massive boulder coral, and coral rubble, sand, macro algae, turf, and other). 
Data from the emergence traps showed that 16 of the 19 most common taxa of zooplankton showed reduced abundances under increased $\mathrm{CO}_{2}$. Additionally, the abundances of 11 of the 19 taxa were positively correlated with the cover of coral rubble or branching coral (Fig. 4), of which branching coral was reduced at the high- $\mathrm{CO}_{2}$ sites.

Nine zooplankton taxa were negatively correlated with massive boulder coral (which are abundant at high $\mathrm{CO}_{2}$ ), sand, macro algae, and/or turf algae. Sand, macro algae, and turf algae were never dominant substrata in the squares at either high- $\mathrm{CO}_{2}$ or control sites (max. $15 \%$ cover), and yet they appeared to provide shelter for some taxa (e.g. Oithonidae and Pontellidae) but were negatively associated with others (e.g. Arietellidae, Paracalanidae, Sapphirinidae). Only four zooplankton taxa showed no substratum preference. This suggests that reduced availability of branching corals at the high- $\mathrm{CO}_{2}$ sites, and increased presence of massive bouldering corals, contributed to the reduction of several zooplankton taxa at the high- $\mathrm{CO}_{2}$ sites.

\section{Other causes for abundance loss}

Altered habitat quality is one explanation for reduced zooplankton abundance, however other direct and indirect causes also likely contribute. Phytoplankton is food for herbivorous and omnivorous taxa (e.g. Acartiidae, Centropagidae, Harpacticoida, Oithoniidae, Oncaeidae, Paracalanidae, Pontelidae, Gastropoda larvae, Polychaeta, and Pteropoda). However, total organic carbon, total nitrogen, chlorophyll $a$, and phaeophytin concentrations did 
not differ between the high- $\mathrm{CO}_{2}$ and control sites ( $p>0.05$ for all phytoplankton). Supplementary Tables 2 and 3 show mean phytoplankton biomass values, and the significance of $\mathrm{CO}_{2}$, reef, and time (day versus night) on affecting phytoplankton biomass). This suggests that food limitation did not control the abundances of the herbivorous and omnivorous taxa. Changes in density or nutritional quality of phytoplankton in response to high- $\mathrm{CO}_{2}\left(\right.$ ref. ${ }^{29}$ ) are unlikely due to the short residency time, although elevated carbon dioxide can promote phytoplankton production ${ }^{30}$. The observed reductions in herbivorous and omnivorous zooplankton suggest that per capita phytoplankton availability may even increase. In contrast, zooplanktivorous zooplankton (e.g. the carnivorous Arietellidae, Corycaeidae, Sapphirinidae, Amphipoda, Decapoda larvae, Isopoda, Mysida, Ostracoda, Chaetognatha, and fish larvae) are likely to experience diminished food abundances, with potential flow-on effects on their abundances.

The impact of ocean acidification on zooplankton swimming behavior is unstudied. Zooplankton motility is a requisite for feeding, avoiding predators, and vertical migration. Our finding that migration behavior was unaffected by high$\mathrm{CO}_{2}$ levels at the high- $\mathrm{CO}_{2}$ sites suggests their ability to access resources and evade predation appears to remain intact. Nevertheless, behavioral responses of individual taxa to high- $\mathrm{CO}_{2}$ cannot be excluded as a contributing mechanism. For example, high- $\mathrm{CO}_{2}$ disrupts discriminatory and swimming behaviors in response to olfactory cues in some tropical reef fish species ${ }^{31,32}$, and similarly unexpected results are possible for some zooplankton taxa.

Zooplankton migration against vertical currents can enrich zooplankton 
near reefs ${ }^{33}$. Although the horizontal tows were not conducted directly over the bubble streams, gas bubbles at the seep sites should have enhanced vertical currents and, hence, zooplankton densities particularly for the fast-swimming larger zooplankton. The consistently lower zooplankton densities near the seep sites, for all taxa, suggest that vertical currents played no major role for explaining the observed differences in zooplankton biomass between high- $\mathrm{CO}_{2}$ and control sites.

\section{Biological consequences for coral reefs and marine ecosystems}

Reduced zooplankton abundances may have far-reaching consequences for marine ecosystems and fisheries. In coral reefs, planktivores are an important trophic guild that includes many reef associated adult and larval fish and the reef building corals. Corals rely on heterotrophy for essential nutrients not acquired through their symbionts for tissue and skeletal growth ${ }^{34,35,36}$. Increasing heterotrophy is one mechanism for some coral species to compensate for the increased energy demand for calcification under ocean acidification ${ }^{37,38}$, and yet this option may be diminished if zooplankton abundances are severely reduced. Of note is that we only investigated macrozooplankton abundances, not microzooplankton or microbes in the water column. Thus, corals that feed on smaller organisms or those few coral species that continually feed during the day and not just at night ${ }^{39}$ may still fare well under reduced abundances of macrozooplankton ${ }^{40,41}$, which may be the case for the massive bouldering corals that are present at the high- $\mathrm{CO}_{2}$ sites in high abundances since they appear to 
not be negatively affected by the documented reduction in macrozooplankton abundances.

We showed that reduced abundances of demersal zooplankton were in part related to indirect ecological effects of ocean acidification, including changes in their day-time habitat, as branching corals and coral rubble were replaced by massive bouldering corals at high- $\mathrm{CO}_{2}$. This indirect effect is specific to reefassociated zooplankton and not relevant for oceanic plankton. However, ecological changes (habitat quality and food web structures) due to ocean acidification may also alter demersal zooplankton communities in other coastal marine ecosystems.

In addition to acidification, increased atmospheric $\mathrm{CO}_{2}$ is warming the oceans $^{42}$, driving some zooplankton species poleward ${ }^{43}$, enlarging oxygen minimum zones, and restricting vertical migration and distribution of some zooplankton taxa ${ }^{44,45}$. Stratification is becoming more pronounced, suppressing vertical mixing and prompting up-welled waters to shoal, which through reductions in nutrients and production can also reduce zooplankton by as much as $80 \% 46$. Our findings outline an additional pathway how zooplankton can be affected by $\mathrm{CO}_{2}$, suggesting that coral reefs and other coastal ecosystems may be more vulnerable than expected to the rising $\mathrm{CO}_{2}$ levels if the very basis of their food webs is diminished.

\section{Methods}




\section{Zooplankton Sampling and Laboratory analysis}

Zooplankton biomass, abundances and community composition were compared between $\mathrm{CO}_{2}$ regimes (control and high- $\mathrm{CO}_{2}$ sites), each at two reefs (Dobu and Upa-Upasina; Milne Bay Province, Papua New Guinea), and expeditions $(1,2,3)$. Samples were collected at night $(2100-0200$ hours local time) and mid-day (1200-1400 hours) for a total of 24 days during three separate expeditions (17 to 27 January 2013, 24 May to 9 June 2013, 29 March to 2 April 2014), using a $100 \mu \mathrm{m}$ Nansen plankton net (aperture: $70 \mathrm{~cm}$ ). Horizontal tows were conducted along $30 \mathrm{~m}$ transects at both $\mathrm{CO}_{2}$ sites and reefs, both over the reef (2-3 m depth) and offshore (50-70 m water depth). At the high- $\mathrm{CO}_{2}$ sites, transects were located along the edge of the seeps but not in the bubble streams to prevent sampling where zooplankton might be disturbed by the bubbles, and to not fill the net with gas bubbles. A hand-held GPS and a HydroBios flowmeter recorded tow distance to determine the volume of water filtered. Three replicate transects were collected at each location. Bulk zooplankton from additional net tows were frozen at $-80^{\circ} \mathrm{C}$ and analyzed for their fatty acid composition using gas chromatography 47,48 .

To compare diurnal patterns, horizontal tows were additionally conducted over a 24-hour period at the high- $\mathrm{CO}_{2}$ and control sites of Upa-Upasina during the third expedition once per week for four weeks, with tows every three hours during daylight hours and every 2 hours during the night.

Daytime habitat preference for three dominant substrata (branching coral, coral rubble, and massive bouldering coral) was tested with emergence traps. 
The traps consisted of nine custom made pyramid-shaped tents $(100 \mu \mathrm{m}$ mesh net, $L \times W \times H: 1 \mathrm{~m} \times 1 \mathrm{~m} \times 0.75 \mathrm{~m}$ ) with detachable codends that had light (3 lumens) fixed inside to attract zooplankton. Three traps were placed over each of the three types of substrata ( $>50 \%$ branching coral, coral rubble, or bouldering coral) during the third expedition at Upa-Upasina. Over the course of 10 days, the 9 traps were placed in random locations over the different substratum types alternating between the high- $\mathrm{CO}_{2}$ and the control site. The high- $\mathrm{CO}_{2}$ site and the control sites were both sampled 5 days each. A photo was first taken of the 1.0 $\mathrm{m}^{2}$ quadrat of substratum before the trap was placed over it. Emergence traps were tethered unsealed to the reef substrata with nylon string. Contamination from external zooplankton was expected to be low (a few organisms per trap per night), since demersal zooplankton emerge upward and are unlikely to crawl under a physical barrier, i.e. the trap. Emergence traps were deployed during daylight hours ( $1300 \mathrm{hrs}$ ) before zooplankton emerged into the water column, and the codends were retrieved 3-4 hours after dark (2100-2200 hrs).

From both the horizontal tows and the emergence traps, the contents of the codends were stored in a $4 \%$ formaldehyde-seawater solution. Later, replicate subsamples were analyzed in the laboratory. Copepods were identified to family level, and non-copepods were identified to class or order. After identification, samples were split in half with a Folsom splitter and half of the sample was placed onto pre-weighed and pre-combusted GF/F $47 \mathrm{~mm}$ filters and Aluminum tins. Samples were dried at $60^{\circ} \mathrm{C}$ for 24 hours before weighing to obtain biomass data ( $\mathrm{mg}$ dry weight $\mathrm{m}^{-3}$ ). 


\section{Seawater Chemistry}

The seawater chemistry at Upa-Upasina and Dobu reefs has been documented previously ${ }^{20,25}$. The $\mathrm{pH}$ at the total scale $\left(\mathrm{pH}_{\mathrm{T}}\right)$ averaged 8.0 at the control sites and 7.8 at the high- $\mathrm{CO}_{2}$ sites. The control sites are exposed to a relatively stable $\mathrm{pH}$ level whereas the high- $\mathrm{CO}_{2}$ sites experience more variable $\mathrm{pH}$ t levels. Water samples were collected during the expeditions and fixed with mercuric chloride solution and later analyzed for their dissolved inorganic carbon (DIC) and total alkalinity $(A T)$ using a Versatile Instrument for the Determination of Total Inorganic Carbon and Titration Alkalinity (VINDTA 3C). DIC and AT were used to calculate other seawater parameters (Supplementary Table 1), including $\mathrm{pH}$ at total scale $(\mathrm{pH})$, partial pressure of carbon dioxide $\left(\mathrm{pCO}_{2}: \mu a t m\right)$, bicarbonate $\left(\mathrm{HCO}_{3}:\right.$ : $\left.\mu \mathrm{mol} \mathrm{kg}{ }^{-1}\right)$, and carbonate $\left(\mathrm{CO}_{3}{ }^{2-:}: \mu \mathrm{mol} \mathrm{kg}{ }^{-1}\right)$ using the Excel macro CO2SYS ${ }^{49}$ under the constraints set by Dickson and Millero ${ }^{50}$.

\section{Phytoplankton in the water column}

Phytoplankton quantity in the water column were compared between control and high- $\mathrm{CO}_{2}$ sites at Dobu and Upa-Upasina reefs to determine the amount of food available to herbivorous zooplankton. Water samples were collected at midnight (0000 hr) and midday (1200 hr) using a Niskin bottle. Onboard the M/V Chertan, $3 \mathrm{~L}$ of water was immediately filtered through $47 \mathrm{~mm}$ GF/F filters and stored in liquid nitrogen. Later in the laboratory, pigments were dark-extracted in $100 \%$ acetone and samples were placed in a fluorometer and 
measured for the quantity of total oceanic carbon (TOC, $\mu \mathrm{g} \mathrm{L}^{-1}$ ), total nitrogen (TN, $\left.\mu \mathrm{g} \mathrm{L}^{-1}\right)$, chlorophyll a $\left(\mu \mathrm{g} \mathrm{L}^{-1}\right)$, and phaeophytin ( $\left.\mu \mathrm{g} \mathrm{L}^{-1}\right)$. Mean TOC, TN, chl a, and phaeophytin values are presented in Supplementary Table 2. Generalized linear models (GLMs) were used to determine the statistical significance of environmental factors ( $\mathrm{CO}_{2}$, reef, time, and interaction terms) on the phytoplankton levels (Supplementary Table 3).

\section{Statistical Analysis}

Abundance data were averaged across replicate transects (or emergence traps) within $\mathrm{CO}_{2}$ levels, reefs and nights. Log ratios (high- $\mathrm{CO}_{2} /$ control) of zooplankton abundance (individuals $\mathrm{m}^{-3}$ ) for each zooplankton taxon were estimated with generalized additive mixed models (GAMM) with log link function and quasipoisson distribution using the predictors $\mathrm{CO}_{2}$ (high- $\mathrm{CO}_{2}$, control), reef (Upa-Upasina, Dobu), and expedition (1,2, 3; Supplementary Table 4).

Redundancy analysis (RDA) was used to assess the relationship between zooplankton communities and environmental variables $\left(\mathrm{CO}_{2}\right.$, reef, and expedition). Zooplankton abundances were $4^{\text {th }}$-root transformed. Permutation tests were used to determine the statistical significances of the environmental variables between the zooplankton communities.

To determine substratum preference of each zooplankton taxon, the photos were digitally adjusted for tilt and size. The percent coverage was estimated for the targeted substrata (coral rubble, branching coral and bouldering coral), as well as for other co-existing groups including sand, macroalgae, and 
turf algae. The influence of the percent coverage of each substratum category,

$\mathrm{CO}_{2}$, reef, and expedition on the abundance of each zooplankton taxon was also evaluated using generalized linear models (GLMs) using a log link function and quasipoisson distribution. 


\section{References}

1. Broecker, W. S. \& Clark, E. Glacial-to-Holocene redistribution of carbonate ion in the deep sea. Science 294, 2152-2155 (2001).

2. Caldeira, K. \& Wickett, M. E. Anthropogenic carbon and ocean pH. Nature 425, 365 (2003).

3. Orr, J. C. et al. Anthropogenic ocean acidification over the twenty-first century and its impact on calcifying organisms. Nature 437, 681-686 (2005).

4. Feely, R. A., Doney, S. C. \& Cooley, S. R. Ocean acidification: Present conditions and future changes in a high- $\mathrm{CO}_{2}$ world. Oceanography 22, 3647 (2009).

5. Richardson, A. J. In hot water: Zooplankton and climate change. ICES J. Mar. Sci. 65, 279-295 (2008).

6. Longhurst, A. R. Role of the marine biosphere in the global carbon cycle. Limnol. Oceanogr. 36, 1507-1526 (1991).

7. Bucklin, A. et al. in Life in the World's Ocean (ed. McIntyre, A. D.) 247-265 (Blackwell Publishing Ltd., 2010).

8. Comeau, S., Gorsky, G., Jeffree, R., Teyssie, J. L. \& Gattuso, J.-P. Impact of ocean acidification on a key Arctic pelagic mollusc (Limacina helicina). Biogeosciences 6, 1877-1882 (2009).

9. O'Donnell, M. J. et al. Ocean acidification alters skeletogenesis and gene expression in larval sea urchins. Mar. Ecol. Prog. Ser. 398, 157-171 (2009).

10. Sheppard Brennand, H., Soars, N., Dworjanyn, S. A., Davis, A. R. \& Byrne, M. Impact of ocean warming and ocean acidification on larval development and calcification in the sea urchin Tripneustes gratilla. PLoS One 5, e11372 (2010).

11. Kurihara, H. \& Ishimatsu, A. Effects of high $\mathrm{CO}_{2}$ seawater on the copepod Acartia tsuensis through all life stages and subsequent generations. Mar. Pollut. Bull. 56, 1086-1090 (2008).

12. Weydmann, A., Søreide, J. E., Kwasniewski, S. \& Widdicombe, S. Influence of $\mathrm{CO}_{2}$-induced acidification on the reproduction of a key Arctic copepod Calanus glacialis. J. Exp. Mar. Bio. Ecol. 428, 39-42 (2012).

13. McConville, $\mathrm{K}$. et al. Effects of elevated $\mathrm{CO}_{2}$ on the reproduction of two 
calanoid copepods. Mar. Pollut. Bull. 73, 428-434 (2013).

14. Hildebrandt, N., Niehoff, B. \& Sartoris, F. J. Long-term effects of elevated $\mathrm{CO}_{2}$ and temperature on the Arctic calanoid copepods Calanus glacialis and C. hyperboreus. Mar. Pollut. Bull. 80, 59-70 (2014).

15. Gaylord, B. et al. Ocean acidification through the lens of ecological theory. Ecology 96, 3-15 (2015).

16. Hamner, W. M. \& Carleton, J. H. Copepod swarms: attributes and role in coral reef ecosystems. Limnol. Oceanogr. 24, 1-14 (1979).

17. Christou, E. D. \& Verriopoulos, G. C. Analysis of the biological cycle of Acartia clausi (Copepoda) in a meso-oligotrophic coastal area of the eastern Mediterranean Sea using time-series analysis. Mar. Biol. 115, 643-651 (1993).

18. González, J. G. Critical thermal maxima and upper lethal temperatures for the calanoid copepods Acartia tonsa and A. clausi. Mar. Biol. 27, 219-223 (1974).

19. Cervetto, G., Gaudy, R. \& Pagano, M. Influence of salinity on the distribution of Acartia tonsa (Copepoda, Calanoida). J. Exp. Mar. Biol. 239, 33-45 (1999).

20. Fabricius, K. E. et al. Losers and winners in coral reefs acclimatized to elevated carbon dioxide concentrations. Nat. Clim. Change. 1, 165-169 (2011).

21. Andersson, A. J. \& Gledhill, D. Ocean acidification and coral reefs: Effects on breakdown, dissolution, and net ecosystem calcification. Ann. Rev. Mar. Sci. 5, 321-348 (2011).

22. Enochs, I. C. et al. Shift from coral to macroalgae dominance on a volcanically acidified reef. Nat. Clim. Change. 5, 1-9 (2015).

23. Alldredge, A. L. \& King, J. M. Distribution, abundance, and substrate preferences of demersal reef zooplankton at Lizard Island Lagoon, Great Barrier Reef. Mar. Biol. 41, 317-333 (1977).

24. Carleton, J. H. Zooplankton and coral reefs: an overview. South Pacific Underw. Med. Soc. 23, 102-107 (1993).

25. Fabricius, K. E., Kluibenschedl, A., Harrington, L., Noonan, S. \& De'ath, G. In situ changes of tropical crustose coralline algae along carbon dioxide gradients. Sci. Rep. 5, 9537 (2015).

26. Kurihara, H., Shimode, S. \& Shirayama, Y. Sub-lethal effects of elevated 
concentration of $\mathrm{CO}_{2}$ on planktonic copepods and sea urchins. $\mathrm{J}$. Oceanogr. 60, 743-750 (2004).

27. Isari, S., Zervoudaki, S., Saiz, E., Pelejero, C. \& Peters, J. Copepod vital rates under $\mathrm{CO}_{2}$-induced acidification: A calanoid species and a cyclopoid species under short-term exposures. J. Plankton Res. 37, 912-922 (2015).

28. Fabricius, K. E., De'ath, G., Noonan, S. \& Uthicke, S. Ecological effects of ocean acidification and habitat complexity on reef-associated macroinvertebrate communities. Proc. R. Soc. B Biol. Sci. 281, 20132479 (2014).

29. Rossoll, D. et al. Ocean acidification-induced food quality deterioration constrains trophic transfer. PLoS One 7, 2-7 (2012).

30. Johnson, V. R. et al. Responses of marine benthic microalgae to elevated CO2. Mar. Biol. 160, 1813-1824 (2013).

31. Munday, P. L. et al. Ocean acidification impairs olfactory discrimination and homing ability of a marine fish. Proc. Natl. Acad. Sci. U. S. A. 106, 18481852 (2009).

32. Kim, H., Spivack, A. J. \& Menden-Deuer, S. pH alters the swimming behaviors of the raphidophyte Heterosigma akashiwo: Implications for bloom formation in an acidified ocean. Harmful Algae 26, 1-11 (2013).

33. Genin, A., Jaffe, J. S., Reef, R., Richter, C. \& Franks, P. J. S. Swimming against the flow: a mechanism of zooplankton aggregation. Science 308, 860-862 (2005).

34. Hamner, W. M., Jones, M. S., Carleton, J. H., Hauri, I. R. \& Williams, D. M. Zooplankton, planktivorous fish, and water currents on a windward reef face: Great Barrier Reef, Australia. Bull. Mar. Sci. 42, 459-479 (1988).

35. Ferrier-Pagès, C., Hoogenboom, M. \& Houlbrèque, F. The role of plankton in coral trophodynamics. Coral Reefs: An Ecosystem in Transition (Springer Science, 2011). doi:10.1007/978-94-007-0114-4

36. Houlbrèque, F. \& Ferrier-Pagès, C. Heterotrophy in tropical scleractinian corals. Biol. Rev. 84, 1-17 (2009).

37. Edmunds, P. J. Zooplanktivory ameliorates the effects of ocean acidification on the reef coral Porites spp. Limnol. Oceanogr. 56, 24022410 (2011).

38. Towle, E. K., Enochs, I. C. \& Langdon, C. Threatened Caribbean coral is able to mitigate the adverse effects of ocean acidification on calcification by increasing feeding rate. PLoS One e0123394 (2015). 
doi:10.1371/journal.pone. 0123394

39. Johannes, R. E. \& Tepley, L. Examination of feeding of the reef coral Porites lobata in situ using time lapse photography. in Proceedings of the 2nd Coral Reef Symposium 127-131 (1974).

40. Wellington, G. M. An experimental analysis of the effects of light and zooplankton on coral zonation. Oecologia 52, 311-320 (1982).

41. Palardy, J. E., Rodrigues, L. J. \& Grottoli, A. G. The importance of zooplankton to the daily metabolic carbon requirements of healthy and bleached corals at two depths. J. Exp. Mar. Bio. Ecol. 367, 180-188 (2008).

42. Barnett, T. P. et al. Penetration of human-induced warming into the world's oceans. Science 309, 284-287 (2005).

43. Hays, G. C., Richardson, A. J. \& Robinson, C. Climate change and marine plankton. Trends Ecol. Evol. 20, 337-344 (2005).

44. Whitney, F. A., Freeland, H. J. \& Robert, M. Persistently declining oxygen levels in the interior waters of the eastern subarctic Pacific. Prog.

Oceanogr. 75, 179-199 (2007).

45. Maas, A. E., Frazar, S. L., Outram, D. M., Seibel, B. A. \& Wishner, K. F. Fine-scale vertical distribution of macroplankton and micronekton in the Eastern Tropical North Pacific in association with an oxygen minimum zone. J. Plankton Res. 36, 1557-1575 (2014).

46. Roemmich, D. \& McGowan, J. Climatic warming and the decline of zooplankton in the California current. Science (80-. ). 267, 1324 (1995).

47. Kattner, G. \& Fricke, H. S. G. Simple gas-liquid chromatographic method for the simultaneous determination of fatty acid and alcohols in wax esters of marine organisms. J. Chromatogr. A 361, 263-268 (1986).

48. Hagen, W. in ICES Zooplankton Methodology Manual (eds. Harris, R., Wiebe, P., Lenz, J., Skjoldal, H. \& Huntley, M.) 113-119 (Academic Press, 2000).

49. Lewis, E. \& Wallace, D. in ORNL/CDIAC-105. Carbon Dioxide Information

Formatted: French (France) Analysis Center. (U.S. Department of Energy, 1998).

50. Dickson, A. G. \& Millero, F. J. A comparison of the equilibrium constants for the dissociation of carbonic acid in seawater media. Deep Sea Res. Part A, Oceanogr. Res. Pap. 34, 1733-1743 (1987). 


\section{Acknowledgements}

The authors thank crew members of the M/V Chertan for help in the field, in particular Obedi Daniel and Robin ('Lei') Luke, along with other members of the Hamamas Team. We also thank the community of Upa-Upasina and Dobu Island for permission to study zooplankton in their reef. Additional thanks to Sam Noonan from the Australian Institute of Marine Science for logistical support, and Holger Auel and Petra Wencke from Bremen University for laboratory help and advice for the biochemical analysis. This project was funded in part by the Erasmus Mundus funded joint doctoral program MARES (FPA 2011-0016), the Great Barrier Reef Foundation's ‘Resilient Coral Reefs Successfully Adapting to Climate Change' Program in collaboration with the Australian Government, the BIOACID Phase II Programme of the German Science Ministry BMBF (Grant 03F0655B), and the Australian Institute of Marine Science.

\section{Author contributions}

JNS, KEF, CR, AC designed the experiment. JNS and KEF did the fieldwork. JNS did the laboratory work. GD, JNS, KEF did the statistical analysis. All authors contributed to writing the manuscript.

\section{Competing financial interests}

The authors declare no competing financial interests.

\section{Materials and Correspondence}


Please address all correspondence and requests for materials to Joy Smith at JZ.Smith@aims.gov.au

\section{Figure Legends}

Figure 1: Differences in zooplankton biomass between control and high- $\mathrm{CO}_{2}$ sites, derived from horizontal net tows. Zooplankton biomass (a) at the two reefs (Dobu and Upa-Upasina) and three expeditions at night, and (b) a 24-h sampling campaign showing the persistence of nightly vertical migration at both the high$\mathrm{CO}_{2}$ and control site of Upa-Upasina reef. Control sites are represented in blue, and high- $\mathrm{CO}_{2}$ sites are represented in red.

Figure 2. Abundance ratios (high- $\mathrm{CO}_{2} /$ control) for selected zooplankton taxa. The circles and bars represent the means and 95\% confidence intervals respectively. The ratios of abundances of zooplankton taxa between the control and the high$\mathrm{CO}_{2}$ sites are significantly different at the $5 \%$ level if their error bars do not include the value 1.0

Figure 3. Differences in communities of nocturnal reef-associated zooplankton between control and high- $\mathrm{CO}_{2}$ conditions at two reefs (Dobu and Upa-Upasina) across three expeditions. The vectors of the redundancy analysis biplots 
represent the directions of increased abundance (individuals $\mathrm{m}^{-3}$ ) of the various taxa. Dots represent average values across three net tows per night and $\mathrm{CO}_{2}$ condition (blue: control, red: high- $\mathrm{CO}_{2}$ ).

Figure 4. Influences of $\mathrm{CO}_{2}$, Reef, Date, and substratum on dominant zooplankton taxa from emergence traps. Substrata are percent cover of: $\mathrm{CR}=$ coral rubble, $\mathrm{BC}=$ branching coral, $\mathrm{MC}=$ massive (bouldering) coral, $\mathrm{SA}=$ sand,

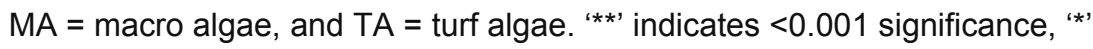
indicates $<0.05$ significance, and empty boxes indicate 'none significance'. For $\mathrm{CO}_{2}$ and the substrata, green and purple boxes indicate positive and negative relationships, respectively. 